\title{
RENDA BÁSICA PERMANENTE: UMA UTOPIA POSSÍVEL
}

Resumo: Conforme cresce a consciência acerca do aprofundamento do fosso de desigualdade e outros problemas estruturais contemporâneos, robustecem-se experimentos, projetos e a discussão sobre programas de renda básica. Com a eclosão da crise econômica provocada pela pandemia de COVID-19, no Brasil, como em outros países, foi implantado programa de auxílio emergencial, de curta duração (Lei 13.982/2020). A adoção dessa medida estimula o debate em torno da ideia de renda básica permanente como política pública. Examinadas brevemente as origens e diferentes versões da proposta de renda básica ao longo da história moderna, discutem-se os três mitos difundidos em torno de programas de renda básica: gerariam desestímulo ao trabalho, seu financiamento seria inviável e esbarrariam em insuperável complexidade e resistência política. Apresentam-se evidências que contrariam tais mitos, concluindo que o país dispõe de recursos financeiros e instituições para garantir renda mínima permanente a todos os brasileiros em condições de vulnerabilidade.

Palavras-chave: Renda básica permanente. Renda mínima universal. Desigualdade. Pobreza. Tributação progressiva.

\section{PERMANENT BASIC INCOME: A POSSIBLE UTOPIA}

Abstract: The more people get aware of the deep gap of inequality and some others contemporary problems, the more empirical tests, projects and the discussion on basic income programs get strengthened. With the disruption of the economic crisis caused by the pandemic of COVID-19, in Brazil as in other countries, a short-term program of emergency assistance was adopted (Law 13.982/2020). This fact stimulates the debate on basic income program in permanent basis, as a public policy. We exam briefly the origins and different versions of basic income proposals along modern history, we discuss the three myths that grew around basic income programs: that they represent a disincentive to work, that it is impossible to finance these programs, and that red tape and political veto would preempt them. We present empirical evidence that contradicts such myths, and conclude that the country has financial resources and institutions to support basic income to every Brazilian in vulnerability conditions.

Keywords: Permanent basic income. Universal minimum income. Inequality. Poverty. Progressive Taxation.

\section{INGRESO BÁSICO PERMANENTE: UMA UTOPIA POSIBLE}

Resumen: A medida que aumenta la conciencia de la brecha cada vez mayor en la desigualdad y otros problemas estructurales contemporáneos, se fortalecen los experimentos, proyectos y la discusión sobre programas de ingreso básico. Con el estallido de la crisis económica provocada por la pandemia de COVID-19, en Brasil, como en otros países, se implementó un programa de ayuda de emergencia a corto

\footnotetext{
1 Universidade do Estado do Rio de Janeiro (UERJ), Faculdade de Ciências Econômicas (FCE), Programa de Pós-Graduação em Ciências Econômicas (PPGCE), Rio de Janeiro, Brasil, lucia.salgado@uerj.br, 0000-0001-6538-2626.
} 
plazo (Ley 13.982 / 2020). La adopción de esta medida estimula el debate en torno a la idea de ingreso básico permanente como política pública. Examinando brevemente los orígenes y las distintas versiones de la propuesta de ingreso básico a lo largo de la historia moderna, se discuten los tres mitos difundidos en torno a los programas de ingreso básico: generarían desánimo para trabajar, su financiación sería inviable y tropezarían con una complejidad y resistencia política insuperables. . Se presenta evidencia que contradice tales mitos, concluyendo que el país cuenta con recursos financieros e instituciones para garantizar ingresos mínimos permanentes a todos los brasileños en condiciones de vulnerabilidad.

Palabras clave: Ingreso básico permanente. Ingreso mínimo universal. Desigualdad. Pobreza. Tributación progresiva.

\section{Introdução}

A quantidade de estudos, experimentos, programas e discussão em torno de uma renda básica ou mínima, condicional ou incondicional já vinha se avolumando desde o inicio do século - parecia que caíra a ficha, afinal, para academia e para governos - tanto de países ricos como em desenvolvimento - de que o aumento alarmante da desigualdade social, a estagnação de crescimento, o desemprego estrutural agravado pelos desafios impostos pela $4^{\underline{a}}$ revolução industrial exigiam mais do que politicas paliativas. Temores de instabilidade social, crescente polarização e descrença na democracia liberal traduzindo efeitos não antecipados da globalização e de décadas de prevalência dos dogmas da religião do mercado reacenderam o interesse sobre o tema. A pandemia de covid-19 que eclodiu em março de 2020, com a dramática crise econômica que vem provocando, tornou urgente e imperiosa a adoção pelos governos de políticas de auxílio às populações mais vulneráveis, assim como àqueles que repentinamente se viram desprovidos de qualquer renda. No Brasil, um programa de renda básica emergencial foi criado pela Lei 13.982/2020, prevendo uma duração de três meses. Contudo, uma vez instituídas tais políticas como resposta à atual crise, resta criada a oportunidade para, com ajuda do debate bem informado, vencer resistências à ideia de uma renda básica permanente e, até mesmo, universal.

\section{Uma ideia quase tão antiga quanto o Brasil}

A ideia de uma renda básica ou renda mínima, condicional ou não, é bem antiga. No Brasil, como política pública foi bravamente defendida por décadas pelo então Senador Eduardo Suplicy. A proposta de uma renda mínima para famílias em situação de vulnerabilidade traduziu-se em experimentos nos anos 1990 na cidade de Campinas e no distrito Federal, condicionada à manutenção das crianças na 
escola. Programa federalizado a partir de 1997, denominou-se Bolsa Escola a partir de 2001, com a entrada em operação do Cadastro Único. O projeto do Senador Suplicy de uma renda básica de cidadania foi finalmente transformado em lei em 2004 (Lei 10.835/2004) unificando-se a Bolsa Escola e auxílios adicionais (Bolsa Alimentação e Auxílio Gás) no programa Bolsa Família.

Originalmente, a ideia de uma renda básica, que retire populações da situação de miséria e fome, nasce com a Idade Moderna e o pensamento humanista. Durante a idade Média, o auxílio aos mais pobres era associado à caridade e institucionalizado pela Igreja, cujas ordens religiosas mantinham, financiadas por doações voluntárias das famílias ricas, casas de acolhimento de toda sorte. Na Idade Moderna, Thomas More em "A Utopia" (1506) 2propõe introduzir o tema da atenção para com os mais pobres na agenda dos Estados organizados, quando o personagem do viajante português narra conversa tida com o Arcebispo de Canterbury, em que defendera a oferta de uma renda mínima com argumento que, ao tempo que valoriza a dignidade humana, já carrega um sentido racional e pragmático: seria uma política mais eficaz contra o crime do que sentenciar à morte os ladrões. Seja por razões humanistas ou pragmáticas, a proposta de um auxílio sistemático e independente dos humores da caridade se transforma pouco depois nas "Poor Laws", instituídas na Inglaterra em 1516, que perduraram por mais de três séculos, sempre condicionadas ao trabalho.

A ideia torna a aparecer no século iluminista, justamente na França das vésperas da Revolução, pelas mãos do Marquês de Condorcet, que entre escritos que até hoje inspiram a economia e a ciência política, deixou manuscrita uma proposta para reduzir a pobreza e a insegurança social, no que seria uma forma rudimental de sistema de seguridade social, (publicado postumamente em 1795) ${ }^{3}$. Partindo de Condorcet, Thomas Paine estende a ideia e teria sido o primeiro tanto a se preocupar com a forma de financiamento dessa despesa como a pensar a renda como universal, propondo um imposto sobre a propriedade da terra cuja arrecadação deveria ser distribuída igualmente à comunidade, sem distinção entre ricos e pobres (considerando-se que originalmente a terra seria propriedade de todos os habitantes do planeta).

Adiante, ainda no mundo das ideias, encontramos uma proposta mais estruturada como política pública, na obra Princípios de Economia Política de John

\footnotetext{
${ }^{2}$ A Utopia, Thomas More, Penguin Clássicos, 2014.

${ }^{3}$ Esboço de um Quadro Histórico dos Progressos do Espírito Humano (1795), M. de Condorcet, Editora Unicamp, 2014.
} 
Stuart Mill. Mill era o que hoje denominaríamos de um liberal progressista - à época pertencente ao grupo denominado "pensadores radicais". De fato, eram ideias avançadas as que defendia em plena era vitoriana (entre as décadas de 1840 e 1860): voto universal, educação pública para meninos e meninas, liberdade de expressão e associação, igualdade entre os gêneros, incluindo direito à propriedade e ao voto. Mill defende a legitimidade das Poor Laws "none needs help so urgently as one who is starving (...) there is the amplest realson for making the relief of so extreme an exigency as certain to those who require it (...)". Contudo, honrando a formação utilitarista, preocupa-se com que essa ajuda seja mínima, de modo a manter o incentivo à busca de renda por meios próprios (ao trabalho, portanto): "The problem to be solved is some of peculiar nicety as well as importance: how to give the greatest amount of needful help, with the smallest encouragement to undue reliance on it."4

A noção de que a sociedade politicamente organizada no Estado tem a obrigação de prover sustento mínimo a seus cidadãos acaba por tomar outro rumo, o que no final do século XIX dará origem à Previdência Social, condicionada também ao trabalho, complementada pela assistência social, condicionada a parâmetros sócio-econômicos de vulnerabilidade, formando o sistema de Seguridade Social conhecido na Europa e nas Américas.

Com isso, a ideia de uma renda básica condicionada ou universal perde apelo, embora continue povoando a mente dos economistas norte-americanos, num amplo espectro ideológico; nos anos 1960, Friedman em $1962^{5}$ propôs substituir o sistema de seguridade social por um imposto de renda negativo, com o que abaixo de determinado nível de renda anual, as pessoas receberiam da receita federal, em vez de pagar6. O autor argumentava que o sistema seria mais simples e barato, por eliminar toda a burocracia associada aos programas sociais (cuja ampliação estava na agenda). Tobin e Galbraith, economistas atentos à concentração de renda defenderam ideias semelhantes ${ }^{7}$.

\footnotetext{
${ }^{4}$ Principles of Political Economy Books IV and V, (1848) J.S. Mill, Penguin Classics, 1985.

${ }^{5}$ Capitalismo e Liberdade (1962), LTC Editora, 2014.

${ }^{6}$ Sobre as distinções conceituais e técnicas entre renda básica incondicional e imposto de renda negativo, ver Basic Income: A Radical Proposal for a Free Society and a Sane Economy. Philippe Van Parijs e Yannick Vanderborght, Harvard university Press, 2017.

${ }^{7}$ Essa discussão nos anos 1960 está bem descrita em "Renda básica: renda minima garantida para o século XXI?" Philippe Van Parijs in Estudos Avançados 14 (40) 2000.
} 


\section{Os mitos em torno de programas de renda básica}

Existem três mitos em torno da ideia de programas de renda básica, com ou sem condicionalidades, que merecem ser examinados mais de perto: renda básica geraria preguiça; seria impossível financiar renda básica permanente e o programa seria de complexidade extrema e esbarraria em resistência política.

\section{Renda básica gera preguiça}

Um dos mitos que se perpetuou sobre a ideia de renda básica é o de que desestimularia o trabalho - a preocupação já estava presente nas Poor Laws, que instituíam o trabalho obrigatório em troca do amparo e foi expressa mais claramente por Stuart Mill, ao mencionar a necessidade de uma renda que suprisse o mínimo para a sobrevivência, mas nada além disso, para não se contrapor ao incentivo ao trabalho. Margareth Tatcher, protagonista junto a Ronald Reagan da onda neoliberal que varreu o Ocidente a partir dos anos 1980, apontava mecanismos de seguridade social em geral e rendas assistenciais em particular como perniciosas para uma sociedade de "homens livres", contrárias à "ética da responsabilidade individual", que impulsionaria o "individuo racional" à prudência e ao esforço pessoal ${ }^{8}$. Experimentos com base científica não confirmam tais temores: Abhijit Banerjee ${ }^{9} \mathrm{e}$ coautores analisaram seis programas de transferência de renda em diversos países $^{10}$ e não encontraram evidências de desestímulo ao trabalho. Um experimento realizado na Finlândia pelo governo entre 2017 e 2018, com dois mil desempregados, também não encontrou evidências de desestímulo à busca de emprego por parte dos receptores de renda. Ao contrário, encontraram-se evidências robustas de aumento do bem-estar, auto-estima e saúde dos receptores. A recorrência dessas evidências empíricas são o melhor argumento para contrapor a uma crença que só agora foi posta à prova.

\footnotetext{
${ }^{8}$ A Nova Razão no Mundo - Ensaios sobre a Sociedade Neoliberal. Christian Laval e Pierre Dardot, Editora Boitempo, 2016.

9 Co-fundador do J-Pal/MIT (Abdul Latif Jameel Poverty Action Lab: Laboratório de Ação contra a Pobreza, ligado ao MIT) e prêmio Nobel de 2019 com Ester Duflo e Michael Kremer por seus estudos empíricos sobre combate à pobreza (utilizando técnicas de experimentos, com amostragem aleatória de grupos de tratamento e controle, acompanhados por cerca de dois anos). Sobre tais técnicas consultar: Running Randomnized Evaluations - a pratical guide - Rachel Glennerster e Kudzai Takavarasha, Pinceton Univ. Press, 2013. Sobre esses e outros experimentos: www.povertyactionlab.org ${ }^{10}$ Os países onde os experimentos com controle randomizados (RCT, na sigla em inglês) foram realizados são Indonésia, Filipinas, México, Nicarágua, Marrocos e Honduras.
} 


\section{É impossível financiar renda básica permanente}

Imaginemos um cenário em que flui o diálogo, posições divergentes são expostas e ouvidas com atenção, busca-se o convencimento, o entendimento em torno de pontos em comum. A sociedade está consciente do mal-estar geral e crescente provocado pela desigualdade social e resolve estabelecer um pacto de solidariedade e harmonia, um novo contrato social que inclua uma radical revisão do sistema tributário, capaz de financiar a provisão de bens públicos e operar como instrumento de redistribuição. Cenário ideal, mas distante. Entre o um mundo ideal e o status quo, há alternativas que merecem ser exploradas; vamos examinar algumas.

No Brasil, apenas a renda do trabalho é tributada de forma progressiva. A renda do capital - lucros e dividendos, ganhos de capital, rendimentos financeiros não. Não por coincidência, pesquisadores que vêm analisando dados de declarações à Receita Federal por pessoas físicas percebem a redução significativa da renda derivada do trabalho e aumento da renda do capital em anos recentes, a ponto de menos da metade dos valores declarados serem rendimentos do trabalho ${ }^{11}$. Harmonizar a tributação de rendas oriundas do trabalho com rendas oriundas do capital e da propriedade não é apenas boa técnica tributária: é imperioso para eliminar a discriminação contra a renda do trabalho. Para isso, a revogação da regra instituída pela Lei 9.249/95, que isentou lucros e dividendos distribuídos e a imposição às rendas do capital das mesmas alíquotas progressivas a que estão sujeitas as rendas do trabalho demandaria apenas legislação ordinária, com entrada em vigor em 01/01/2021. Estudos técnicos indicam o potencial de arrecadação de $\mathrm{R} \$ 59,7$ bilhões por ano com essa medida ${ }^{12}$.

\footnotetext{
${ }_{11}$ Marcelo Medeiros e Fabio Castro "A composição da renda no topo da distribuição: evolução no Brasil entre 2006 e 2012 a partir de informações do imposto de renda" in Economia e Sociedade, Unicamp, agosto 2018 e José Roberto Afonso,"Imposto de renda, baixo e diferenciado" in Conjuntura Econômica, FGV, novembro de 2016.

12 Tramitam no Congresso grande número de projetos de lei, de autoria do Legislativo, prevendo a revogação dessa isenção e a aplicação da tabela progressiva a que estão sujeitas as rendas do trabalho aos recebimentos de lucros e dividendos por parte de pessoas físicas. Destacam-se o PL 2.742/20 do senador José Serra e o PL 3.190/2020 do Senador Eduardo Braga. As entidades representantes de auditores fiscais da Receita Federal reunidas no Unafisco têm subsidiado o Legislativo com estudos que apontam, em especial, para a estimativa de $\mathrm{R} \$ 59,7$ bilhões/ano de arrecadação apenas com a revogação da isenção para lucros e dividendos. ("Auditores Fiscais propõe medias de impacto tributário" Valor Econômico, caderno Valor Investe, Edna Simão, Brasília, 17/02/2020).
} 
Outras possibilidades, complementares ou alternativas, seriam a elevação da alíquota de contribuição social sobre lucro líquido para instituições financeiras ${ }^{13}$ para $27,5 \%{ }^{14}$ ou a instituição de uma contribuição extraordinária, de $27,5 \%$ sobre lucros líquidos para grandes conglomerados, financeiros ou produtivos, a partir de determinado patamar, vamos dizer, lucros líquidos superiores a 1 bilhão de reais.

Dentre as diversas propostas resultantes de estudos técnicos encaminhados ao Legislativo e autoridades econômicas por entidades representativas dos auditores fiscais ${ }^{15}$, destaca-se 0 acréscimo temporário de $15 \%$ na CSLL (Contribuição Social sobre o Lucro Líquido) e de mais 4\% na Cofins (Contribuição para o Financiamento da Seguridade Social) para as instituições financeiras, o que elevaria, segundo os cálculos, em $\mathrm{R} \$ 38$ bilhões a arrecadação anual. Para efeito de cobertura da extensão até dezembro de 2020 do auxílio emergencial, seria necessária a adoção de um empréstimo compulsório, de validade imediata, equivalente à elevação de alíquotas propostas para as contribuições financeiras (COFINS e CSLL).

Como exercício meramente ilustrativo do potencial arrecadador de uma contribuição extraordinária sobre lucros líquidos (no mesmo patamar da alíquota máxima de imposto de renda incidente sobre pessoas físicas, 27,5\%), consideremos apenas as cinco maiores instituições bancárias do país: Itaú-Unibanco, Bradesco, Banco do Brasil, Caixa Econômica Federal e Santander. As cinco instituições concentram $83,7 \%$ das operações de crédito bancário e $83,4 \%$ dos depósitos no país. O Banco Central monitora em especial esse grupo "(...) por causa da relevância do segmento bancário comercial, que conta com as cinco maiores instituições financeiras, os indicadores de concentração são determinados em grande parte pela concentração desse conjunto."16 O lucro líquido apurado pelas cinco instituições em 2019 foi de $R$ \$ 105,88 bilhões, de onde a arrecadação obtida com uma contribuição extraordinária sobre lucro líquido das instituições financeiras partiria desse montante de $\mathrm{R} \$ 29,12$ bilhões, contando aqui apenas com a contribuição dos cinco maiores bancos comerciais.

Cobrar alíquotas de impostos diferenciadas para setores econômicos específicos atende perfeitamente ao princípio tributário da isonomia, previsto no texto constitucional.

\footnotetext{
${ }^{13}$ Além de empresas de seguro e capitalização, que hoje recolhem 15\% de CSLL (Lei 13.169/2015).

${ }^{14}$ A definição de uma alíquota da ordem de $27,5 \%$ usa como parâmetro a alíquota máxima em vigor para o imposto de renda da pessoa física.

15 Ver nota 9.

${ }^{16}$ Relatório de Economia Bancária, Banco Central do Brasil, maio de 2020, pp 125-126.
} 
Recente decisão unânime ${ }^{17}$, o Supremo Tribunal Federal (STF) pacificou a controvérsia que ainda pairava sobre o tema, ao acompanhar o voto do relator em duas ações que contestavam a cobrança de CSLL diferenciada para o sistema financeiro. Assim se pronunciou o relator Luís Fux:

Tributar de maneira diferenciada o lucro dos segmentos financeiros e de seguros nada mais é do que escolher o signo representativo daquelas classes económicas para ser objeto de incidência de tributação.

Finalmente, ainda como fontes de financiamento para a adoção de uma renda básica em caráter permanente, há que se regulamentar o Imposto sobre Grandes Fortunas (IGF), previsto desde 1988 na Constituição Federal (Art. 153), a valer a partir de janeiro de 2021. Da mesma forma que com relação à elevação de alíquotas sobre contribuições financeiras descrita acima, seria possível instituir empréstimo compulsório sobre essas mesmas grandes fortunas para efeito em 2020, instrumento legal previsto também na Constituição para atender a necessidades urgentes diante de quadro de calamidade pública - como o que caracteriza a crise econômica provocada pela pandemia de Covid-1918. No Senado, tramitam atualmente quatro projetos para regulamentar o dispositivo. Cálculos realizados pelas entidades de auditores fiscais indicam o potencial de arrecadação de $R \$ 40$ bilhões para alíquotas de 1\%,2\% e 3\% aplicadas progressivamente a patrimônios pessoais superiores a $\mathrm{R} \$ 20$ milhões $^{19}$.

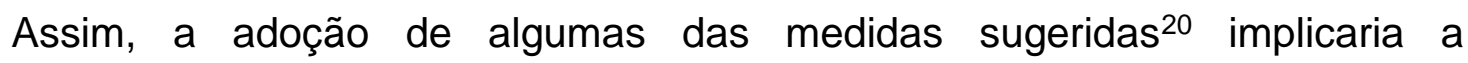
arrecadação adicional da ordem de $\mathrm{R} \$ 138$ bilhões, o equivalente a 1,9\% do PIB. Seria um acréscimo equivalente a $9 \%$ com relação à arrecadação bruta de impostos e contribuições em 2019. A par de financiar renda básica permanente, o ganho em arrecadação permitiria reduzir a carga tributária sobre micro e pequenas empresas, doze milhões de pequenos negócios que representam 99,1\% das empresas no país e respondem por mais da metade dos empregos formais, $54 \%$, de acordo com os dados mais recentes divulgados pelo SEBRAE ${ }^{21}$.

\footnotetext{
17 Processos ADins 4.101 e 5.485, en Sessão plenária de 18/06/2020.

$18 \mathrm{O}$ patrimônio pessoal é declarado anualmente à Secretaria de Receita Federal e consiste, além da riqueza financeira e propriedade de ações e cotas, de imóveis de lazer, fazendas, terrenos, aviões particulares, lanchas, helicópteros, automóveis de luxo, ativos que contribuem para a sociedade apenas, anualmente, com os respectivos impostos estaduais ou municipais de propriedade de veículos, terrenos e imóveis rurais ou urbanos.

19 "Senado debate quatro propostas de imposto sobre grandes fortunas" Senado Notícias 27/03/2020, www12.senado.leg.br

${ }^{20}$ Considerando apenas as propostas submetidas ao Legislativo pela Unifisco, referentes ao IGF e a alíquotas adicionais de CSLL e COFINS.

${ }^{21}$ Serviço Brasileiro de Apoio às Micro e Pequenas Empresas, www.sebrae.org.br, dados de fevereiro de 2020.
} 


\section{Programa é de complexidade extrema e esbarra em resistência política}

Como observou em recente artigo Dani Rodrik - com a sagacidade usual: "Não há nada como uma pandemia para evidenciar tanto as imperfeições dos mercados diante de problemas de ação coletiva quanto a importância da capacidade do Estado de reagir a crises e proteger a população ${ }^{22}$. Se a aguda concentração de renda, o fosso de desigualdade social e as alarmantes taxas de desemprego não incomodavam parcela das elites brasileiras ${ }^{23}$, a pandemia de covid-19 jogou luz sobre uma realidade da qual não é mais possível fugir. A agilidade com que foi ampliado e aprovado o programa de renda básica emergencial no Congresso (Lei 13.982/2020), assim como as iniciativas de doações por parte de grandes empresas do setor produtivo e financeiro em dimensão jamais vista no país, são indicações de que cresce a consciência da responsabilidade de cada um, à sua medida, com a coletividade.

Quanto a dificuldades logísticas e operacionais para fazer chegar a renda a todos os elegíveis, de fato seriam hercúleas não tivessem sido em grande parte já superadas com o formidável esforço de construção de dois mecanismos institucionais da mais alta qualidade, ao longo das últimas décadas: o primeiro deles é o Cadastro Único (CadUnico), que identifica e caracteriza os cidadãos elegíveis para programas de assistência, aqueles com renda mensal igual ou menor a meio salário mínimo per capta e renda familiar mensal de até três salários mínimos. Diversos programas sociais federais utilizam o cadastro único, com diferentes critérios de elegibilidade. Até o início de 2020, o CadUnico registrava 28 milhões de famílias, representando 76 milhões de pessoas ${ }^{24}$.

O segundo é o Sistema Único de Assistência Social (SUAS), que coordena, organiza e orienta a oferta dos programas de assistência, serviços e benefícios, com enorme capacidade de capilarização, visto que os serviços são diretamente prestados pelos entes federados, municípios e organizações complementares voltadas para a assistência social. O portão de acesso aos serviços e benefícios por parte da população mais vulnerável é proporcionado pelos Centros de Referência de

\footnotetext{
22 "There is nothing like a pandemic to highlight markets' inadequacy in the face of collective action problems and the importance of state capacity to respond to crises and to protect people." "Making the Best of a Post-Pandemic World" in Project Syndicate Dani Rodrik May, 12, 2020. www.projectsyndicate.org

${ }^{23}$ Elites entendidas aqui no seu sentido sociológico elementar, como aqueles grupos ocupantes dos extratos mais elevados de renda, educação, informação e capacidade de influência sobre decisões públicas.

24 Mensagem Presidencial ao Congresso, por ocasião da abertura dos trabalhos legislativos, 03/02/2020, www.camara.gov.br
} 
Assistência Social (CRAS); são 8.405 unidades espalhadas pelo pais, sendo $90 \%$ delas financiadas por recursos federais (7.455 unidades). Atendem cerca de 29 milhões de domicílios ${ }^{25}$.

A ausência de uma coordenação centralizada e articulada, um comitê de crise, com representantes dos poderes e contato direto com os entes federados, levou a que a operacionalização do atual programa de renda básica fosse deixado a cargo de uma única instituição financeira, a Caixa Econômica Federal (CEF), com o cadastramento dependente de recursos de informática e comunicação que nem estão disponíveis no estado da arte por parte da empresa pública Dataprev, responsável pelo processamento de informações e homologação de dados dos demandantes, nem são acessíveis para ao menos $20 \%$ dos lares no país ${ }^{26}$. Mesmo entre aqueles com acesso à internet, 13,6 milhões encontraram dificuldades para realizar cadastro por conta de problemas com o $\mathrm{CPF}^{27}$.

Os resultados de evidente ineficiência e ineficácia são de conhecimento público: filas intermináveis, expondo os cidadãos ao contágio pelo vírus e ao sofrimento de dias e noites de espera; falhas repetidas, congestionamento no tráfego de dados, demora e erro na verificação e cruzamento de dados entre repartições públicas, de sorte que, passados noventa dias do início do programa, mais de dez milhões de cidadãos que solicitaram o auxílio sequer receberam a primeira parcela ${ }^{28}$.

Todas essas dificuldades teriam sido rapidamente superadas caso tivesse sido mobilizado o sistema SUAS, em particular as CRAS, que se localizam justamente em áreas onde há maior contingente de população em situação de vulnerabilidade e dispõe de equipes interdisciplinares volantes altamente preparadas. As CRAS, em um cenário alternativo de articulação e coordenação de esforços, poderiam ter inscrições e atualizações no CadUnico, poderiam ter auxiliado aqueles com dificuldade de acesso ao benefício por problemas com o CPF e o registro eleitoral. Os mais vulneráveis conhecem e utilizam os serviços das CRAS que, mais do que qualquer outra instituição, poderiam chegar até aqueles

\footnotetext{
${ }^{25}$ Rede de Pesquisa Solidária, Nota Técnica n.5 do Centro de Estudos da Metrópole, FFLCHUSP/FAPESP, 21/05/2020.

${ }^{26}$ Estima-se que 7,4 milhões de pessoas elegíveis para o auxílio não tem acesso à internet. Ver nota 24.

27 "Governo regularize 13,6 milhões de CPFs de pessoas que tiveram problemas com pedidos de auxílio emergencial" 17/04/2020, www.oglobo.globo.com

28 'Mais de dez milhões de pessoas ainda não conseguiram receber o auxílio emergencial" O Globo, 09/06/2020 www.g1.globo.com
} 
ainda não inscritos no CadUnico, quase metade dos 60 milhões de pessoas que necessitam de auxílio.

\section{O caminho para a renda básica universal passa por tributar a economia digital}

Os sistemas tributários em vigor em países desenvolvidos e em desenvolvimento foram desenhados para uma economia baseada na produção e distribuição de bens físicos e serviços, pagos por pessoas físicas ou jurídicas, conforme seu consumo. A expansão da economia digital no século XXI, no que se tem denominado de $4^{a}$ Revolução Industrial, o surgimento de plataformas, criando mercados de múltiplos lados, unindo negócios a negócios e a consumidores, com métodos de monetização ${ }^{29}$ inovadores, impôs novos desafios à arrecadação tributária para financiar a provisão de bens e serviços públicos. A destruição criadora proporcionada pelas soluções eletrónicas para oferta e distribuição de bens e serviços em escala global, que tendem a eliminar proporção significativa de negócios locais, tem implicado também importante redução da base tributária.

Motivada pela necessidade de adaptar os sistemas tributários à nova realidade, a OECD (Organização de Países para o Desenvolvimento Econômico), instituição dos países desenvolvidos que realiza estudos e propõe boas práticas de políticas para os países que a compõe (e também para aqueles em desenvolvimento) vem conduzindo cuidadoso estudo ${ }^{30}$ para construir uma proposta capaz de obter consenso dos governos dos países integrantes para erosão da base fiscal. Os fatores já claramente identificados como responsáveis por essa erosão são as transferências de lucros e registros de ativos de empresas transnacionais em geral e, em particular, empresas de tecnologia em paraísos fiscais.

É fato notório que as grandes empresas de tecnologia (conhecidas pelo jargão Big Techs) não apenas operam praticamente livres de impostos, mas gerenciam suas atividades globais de sorte a registrar ativos em países onde a carga tributária é zero (nas Bahamas e llhas Cayman, por exemplo) ou próxima de zero (Luxemburgo, Singapura, Chipre e Irlanda) ${ }^{31}$.

\footnotetext{
${ }^{29}$ Métodos de monetização referem-se à forma de remuneração adotada no modelo de negócio, distinta da regra tradicional de atribuição direta de um preço ao bem ou serviço adquirido.

${ }^{30}$ Cujas estapas são regularmente submetidas à consulta pública.

31 The Triumphe of Injustice - How the Rich Dodge Taxes and How to Make them Pay Emmanuel Saez e Gabriel Zucman, Norton Co, 2019.
} 
Os esforços da OCDE, com apoio de organizações e estudiosos debruçados sobre o problema $^{32}$ vão no sentido de se concluir o desenho de uma proposta ${ }^{33}$ para que, ainda no curso de 2020, seja possível um acordo global envolvendo os países desenvolvidos integrantes do G-20 e emergentes como Brasil, India, Indonésia e Turquia.

Dos principais aspectos da proposta da OCDE destacam-se a obrigação de que as empresas globais reportem não mais de forma agregada, mas discriminados país e país, os lucros e impostos pagos às autoridades fiscais ${ }^{34}$ e a redefinição do fato gerador do tributo como sendo a atividade realizada em cada país, independente da presença formal da empresa. Assim, seria possível a definição de uma alíquota (entre $12,5 \%$, como patamar mínimo, e $25 \%$ ou mesmo $30 \%$ ) uniforme para todos os países, de sorte a que os países passassem a cobrar a diferença entre o imposto cobrado no local onde estão registrados ativos e lucros e a sua jurisdição (o que por si já eliminaria a atratividade da transferência de lucros e ativos para paraísos fiscais). Em estudo recente, estimou-se que, globalmente, $40 \%$ dos lucros das empresas transnacionais tem seus lucros registrados em paraísos fiscais.

isso corresponde a cerca de U\$ 800 bilhões em rendimentos obtidos na França, Estados Unidos e Brasil, que terminam sendo registrados nas Ilhas Cayman, Luxemburgo ou Singapura, usualmente [tributados] a taxas entre $5 \%$ e $10 \%$." pp. 78 (tradução livre) ${ }^{35}$

As estimativas mais recentes da OCDE de arrecadação global, tão logo seja operacionalizado esse acordo, são da ordem de US\$100 bilhões/ano. Empresas de tecnologia possuem proporcionalmente mais ativos intangíveis (patentes, know-how, marcas etc.), facilmente transferíveis entre jurisdições. O acordo proposto pela OCDE se celebrado eliminaria o incentivo à alocação de ativos e registro de resultados em países diferentes daqueles de origem e/ou onde são realizadas as transações efetivas.

Em paralelo, tramita na Câmara de Deputados, projeto da autoria de João Maia (PL/RN), o PL 2.358/2020, que institui a Contribuição sobre o Domínio Econômico incidente sobre a receita bruta de serviços digitais prestados pelas grandes empresas de tecnologia (CIDE Digital) ${ }^{36}$. As chances de sucesso de se

\footnotetext{
32 Ver, principalmente, www.taxjusticenow.org e www.icrict.com

${ }^{33}$ A proposta está em fase final de elaboração, restando apenas definir as alíquotas de impostos que servirão de referência para os países do G-20 e evitarão a Guerra Fiscal.

${ }^{34}$ Saez e Zucman, assim como os economistas integrantes do grupo ICRICT, liderados por Joe Stiglitz e Thomas Piketty entendem insuficiente esse grau de transparência, advogando publicização de tais resultados discriminados país e país.

35 "The Missing Profits of Nations" National Bureau of Economic Research Working Paper n. 24701, Thomas Tørlsøv, Ludvig Wier, e Gabriel Zucman, 2018

${ }^{36}$ www.camara.leg.br, projeto de lei apresentado em 04/05/2020.
} 
chegar a um acordo de tributação global a partir da proposta da OCDE são imponderáveis neste momento. A proposta, contudo, foi reforçada pelas recomendações do ICRICT (Comissão Independente para a Reforma da Tributação Internacional de Corporações), nas vozes de Joseph Stiglitz e Thomas Piketty, dentre outros economistas de renome internacional que compõe o comitêe ${ }^{37}$, em relatório contendo medidas para a recuperação sustentável da economia póspandemia de Covid-19. As medidas propostas são ainda mais fortes, envolvendo taxação internacional de grandes empresas, gigantes digitais e grandes fortunas, alem da extinção dos paraísos fiscais.

Independentemente dos resultados de acordos internacionais, verifica-se que o pais dispõe de alternativas para enfrentar também os desafios impostos pela economia digital.

\section{Considerações finais}

Temos recursos financeiros em potencial, recursos institucionais subaproveitados e evidências empíricas de que um programa de renda básica é o caminho para uma sociedade melhor, mais serena e mais justa. Em futuro próximo poderemos contar com a arrecadação tributaria hoje inexistente sobre as receitas obtidas no território brasileiro pelas Big Techs com propaganda, venda de dados de usuários e intermediação de negócios. Dos 60 milhões de pessoas que compõe 0 universo estimado de elegíveis para programas de assistência, 17,8 milhões já estão inscritos no Programa Bolsa Família (PBF), 4,7 milhões são idosos e portadores de deficiência que recebem o benefício de prestação continuada (BPC). Restam 37,5 milhões. Um último exercício ilustrativo: supondo que cada família inscrita no PBF receba o valor médio, $R \$ 190$ e supondo um valor de renda mínima inicial de $R \$ 200$ mensais ${ }^{38}$, o gasto adicional para garantir no orçamento público essa renda mínima seria de $R \$ 90,204$ bilhões. Lembrando que somamos $R \$ 138$ bilhões de arrecadação adicional com as medidas propostas acima, percebe-se que está na esfera do possível transformar o país numa nação solidária, onde nenhum brasileiro passe fome.

A hora é agora.

${ }^{37}$ O relatório do IRICT foi apresentado em 15/06/2020 e está disponível em www.ICRICT.com ${ }^{38} R \$ 120$ reais/ano adicionais para os já inscritos no PBF e $R \$ 2.400 /$ ano para aquelas pessoas que não recebem nem BF nem BPC. 


\section{Referências}

Afonso, José Roberto "Imposto de renda, baixo e diferenciado" in Conjuntura Econômica, FGV-RJ, novembro de 2016.

Banco Central do Brasil Relatório de Economia Bancária, Brasilia - DF, maio de 2020.

Condorcet, Marquis de Esboço de um Quadro Histórico dos Progressos do Espírito Humano (1795), Editora Unicamp, 2014.

Friedman, Milton Capitalismo e Liberdade (1962), LTC Editora, 2014.

Glennerster, Rachel and Takavarasha Kudzai Running Randomnized Evaluations - a pratical guide, Pinceton University Press, 2013.

Laval, Christian e Dardot. Pierre A Nova Razão no Mundo - Ensaios sobre a Sociedade Neoliberal, Editora Boitempo, 2016.

Medeiros, Marcelo e Castro, Fabio "A composição da renda no topo da distribuição: evolução no Brasil entre 2006 e 2012 a partir de informações do imposto de renda" in Economia e Sociedade, Unicamp, agosto 2018.

Mill, John Stuart. Principles of Political Economy Books IV and V, (1848) Penguin Classics, 1985.

More, Thomas. A Utopia, (1516), Penguin Clássicos, 2014.

Saez, Emmanuel and Zucman, Gabriel, The Triumphe of Injustice - How the Rich Dodge Taxes and How to Make them Pay Norton Co, 2019.

Rede de Pesquisa Solidária, Nota Técnica n.5 do Centro de Estudos da Metrópole, FFLCHUSP/FAPESP, 21/05/2020.

Rodrik, Dani "Making the Best of a Post-Pandemic World" in Project Syndicate May, 12, 2020. www.project-syndicate.org

Tørlsøv, Thomas, Wier, Ludvig and Zucman, Gabriel, The Missing Profits of Nations" National Bureau of Economic Research Working Paper n. 24701, Washington - DC, 2018.

Van Parijs, Philippe "Renda básica: renda mínima garantida para o século XXI?" in Estudos Avançados 14 (40) 2000.

Van Parijs, Philippe and Vanderborght, Yannick, Basic Income: A Radical Proposal for a Free Society and a Sane Economy. Harvard University Press, 2017.

\section{NOTAS DE AUTOR}

\section{CONTRIBUIÇÃO DE AUTORIA}

Lucia Helena Salgado - Concepção. Coleta de dados, Análise de dados, Elaboração do manuscrito, revisão e aprovação da versão final do trabalho. 
CONSENTIMENTO DE USO DE IMAGEM

Não se aplica.

APROVAÇÃO DE COMITÊ DE ÉTICA EM PESQUISA

Não se aplica.

\section{CONFLITO DE INTERESSES}

Não se aplica.

\section{LICENÇA DE USO}

Este artigo está licenciado sob a Licença Creative Commons CC-BY. Com essa licença você pode compartilhar, adaptar, criar para qualquer fim, desde que atribua a autoria da obra.

\section{HISTÓRICO}

Recebido em: 21-06-2020

Aprovado em: 05-07-2020 